\title{
Pengarsipan Digital Sebagai Wujud Optimalisasi Manajemen Audit Persuratan di Sekolah
}

\author{
Sunarni*, Maulana Amirul Adha, Alma Bethris Kusvitaningrum, Della Nadhia \\ Agustina, Dita Andriani, Firda Dwi Pratiwi, Rosa Safianti \\ Universitas Negeri Malang, Malang, Jawa Timur, Indonesia
}

Corresponding author: Sunarni (e-mail: sunarni.fip@um.ac.id)

\begin{abstract}
Abstrak: Pada era saat ini penggunaan teknologi dalam bidang apapun sangat diperlukan. Bersikap adaptif dengan cara mengikuti perkembangan zaman dapat terlihat melalui kegiatan pengarsipan. Pengarsipan yang dulunya menyimpan berkas fisik dan mencatat kodenya secara manual, kini bisa dilakukan dengan menyimpannya dalam bentuk data digital. Penelitian ini bertujuan untuk menggali secara mendalam pengarsipan digital sebagai wujud optimalisasi manajemen audit persuratan di SMP Islam Ma'arif 02 Kota Malang. Penelitian ini menggunakan pendekatan kualitatif. Teknik pengumpulan data dalam penelitian ini menggunakan observasi dan wawancara dengan informan kunci yaitu kepala sekolah. Hasil penelitian ini menunjukkan bahwa pengarsipan digital membantu dan memudahkan sekolah dalam melaksanakan manajemen audit persuratan. Penelitian ini merekomendasikan bahwa kegiatan pengarsipan digital yang baik membutuhkan dukungan sumber daya manusia yang mampu mengoperasikan secara optimal aplikasi pengarsipan digital. Dukungan fasilitas sekolah juga dibutuhkan agar pengarsipan digital berjalan dengan efisien.
\end{abstract}

Kata Kunci: pengarsipan, pengarsipan digital, aplikasi pengarsipan digital

\section{Digital Filing as a Form of Optimization of Educational Correspondence Audit Management at School}

\begin{abstract}
In the current era, the use of technology in any field is necessary. By keeping up with the times, the archiving process that used to store physical files and record the code manually can now be done by storing them in the form of digital data. This study aims to explain the application of digital archiving applications as a form of optimization activities for correspondence audit management at SMP Islam Ma'arif 02 Malang City. This research is a qualitative descriptive study using data collection techniques in the form of observation and interviews with the principal as key informant. The results of this study indicate that utilizing digital archiving applications is very helpful and facilitates schools in optimally implementing correspondence audit management. There are many benefits and advantages that the school feels when implementing this filing application. The existence of assistance and support from the school from the participation process in the training program is also a form of optimizing the implementation of archiving audits. This study recommends that to carry out good digital archiving activities, it is necessary to support human resources who are able to optimally operate the application. School facility support is also recommended for efficient digital archiving.
\end{abstract}


Keywords: archiving, digital archiving, digital archiving applications

\section{PENDAHULUAN}

Pada era saat ini penggunaan teknologi dalam bidang apapun sangatlah diperlukan. Terutama dalam bidang pendidikan, idealnya mengikuti dan memanfaatkan teknologi untuk pelaksanaan proses pencapaian tujuan pendidikan (Dubey, 2016). Tak hanya fokus dalam proses pembelajaran saja namun dalam pelaksanaan organisasi sekolah juga memanfaatkan teknologi (Darmaji et al., 2020; Ghavifekr et al., 2014). Penelitian ini membahas mengenai pemanfaatan teknologi dalam tata persuratan dan pengarsipan sehingga mampu mengoptimalisasikan proses audit. Dengan mengikuti perkembangan zaman, proses pengarsipan yang dulunya menyimpan berkas fisik dan mencatat kodenya secara manual kini bisa dilakukan dengan menyimpannya dalam bentuk data digital (Cheng, 2018; Hammond, 2014). Undang-Undang Nomor 43 Tahun 2009 Pasal 1 Ayat 2 tentang Kearsipan menjelaskan bahwa arsip merupakan rekaman kegiatan atau suatu peristiwa dalam bentuk serta media yang sesuai dengan perkembangan teknologi informasi dan komunikasi yang dibuat dan diterima oleh lembaga negara, pemerintah daerah, lembaga pendidikan, perusahaan, organisasi politik, organisasi kemasyarakatan, dan perseorangan dalam kehidupan bermasyarakat, berbangsa, dan bernegara.

Pengarsipan yang sebelumnya menggunakan media kertas saat ini bisa dilakukan dengan pengarsipan digital. Pengarsipan digital merupakan proses penyimpanan arsip melalui media komputer dan pendukungnya (Berisha, 2015). Arsip digital atau arsip elektronik merupakan arsip yang disimpan serta diolah dengan menggunakan suatu format tertentu dan hanya dapat menggunakan media komputer untuk memprosesnya (Muhidin et al., 2018). Kegiatan mengkonversi dari media lembar kertas menjadi lembar elektronik disebut dengan alih media. Setelah proses alih media, berbagai file-file tersebut disimpan dalam media elektronik seperti CD, DVD, Flashdisk, Harddisk, dan lainnya. Penyimpanan file-file ini dilengkapi dengan database yang nantinya dapat dibentuk menjadi suatu sistem arsip digital yang meliputi fasilitas pengelompokan, penamaan file hasil alih media, serta pengaturan (Latif \& Pratama, 2015; Zulkarnain \& Sumarsono, 2015). Tingginya produktivitas suatu organisasi (Arifin et al., 2018; Saputra et al., 2019), maka perlu ditingkatkan pula pelayanan administrasi dalam bidang tata persuratan agar dapat menunjang kelancaran kegiatan organisasi yang lebih efektif dan efisien. Pentingnya kegiatan administrasi tata persuratan, sangat berpengaruh terhadap ketepatan dan kecepatan dalam pemberian informasi yang berguna dalam 
pengambilan keputusan oleh pimpinan dalam hal ini kepala sekolah (Garza et al., 2014; Lindqvist \& Pettersson, 2019).

Audit merupakan suatu kegiatan yang sistematis serta objektif dari bukti-bukti yang bersangkutan dengan pernyataan tentang suatu kegiatan untuk memastikan tingkat hubungan dari pernyataan tersebut dengan kriteria yang telah ditentukan, hingga kemudian mengkomunikasikan hasil yang diperoleh tersebut kepada pihak yang berkepentingan (Kettunen, 2012; Triwiyanto \& Nurabadi, 2015). Audit manajemen merupakan kegiatan yang dilakukan untuk menilai keefektifan operasi suatu lembaga. Hal tersebut dilakukan untuk menilai serta mengetahui apakah kegiatan berjalan dengan efektif dan efisien sehingga bisa mencapai tujuan yang ditetapkan.

Audit pengarsipan termasuk ke dalam audit operasional yang merupakan proses pemeriksaan atas sebagian ataupun semua prosedur dan metode operasional suatu organisasi untuk menilai efisiensi, efektifitas dan ekonomisnya. Tujuan diadakannya audit ini untuk meningkatkan suatu program serta aktivitas yang masih perlu adanya perbaikan agar dapat berjalan secara efektif dan efisien dalam memberikan pelayanan. Artinya hasil kegiatan audit dapat dijadikan sebagai tolak ukur kinerja lembaga serta sebagai bahan evaluasi kinerja lembaga tersebut (Lindquist \& Huse, 2017; Russel, 2012). Setiap lembaga membutuhkan adanya audit untuk mengetahui keefektifan dan keefisienan pengelolaan yang dilakukan, termasuk pada lembaga pendidikan. Berdasarkan jabaran tersebut adanya aplikasi pengarsipan digital di sekolah menjadi penting guna membantu proses audit, sehingga diharapkan mampu mengelola berbagai surat serta mampu memenuhi kebutuhan informasi secara cepat dan tepat.

\section{METODE PENELITIAN}

Penelitian ini merupakan penelitian deskriptif kualitatif yang menggambarkan situasi atau objek dalam fakta yang sebenarnya secara sistematis. Penelitian deskriptif merupakan metode penelitian yang digunakan untuk meneliti kelompok manusia, objek, kondisi, dan sistem pemikiran untuk masa yang akan mendatang (Creswell, 2018). Sementara penelitian kualitatif merupakan prosedur penelitian yang menghasilkan data deskriptif berupa kata-kata yang ditulis dari orang-orang atau perilaku orang sesuai dengan fakta yang ada di lapangan (Ulfatin, 2015).

Pendekatan tersebut digunakan sebab tujuan penelitian ini adalah untuk menjelaskan penerapan aplikasi pengarsipan digital sebagai salah satu wujud dari kegiatan optimalisasi manajemen audit persuratan di SMP 02 Islam Ma'arif Kota Malang. Penelitian ini dilaksanakan di SMP Islam Ma'arif 02 Kota Malang. Teknik pengumpulan data dalam penelitian ini yakni observasi dan wawancara, dengan Informan kunci dalam penelitian ini yakni kepala sekolah 
SMP Islam Ma'arif 02 Kota Malang. Pengecekan keabsahan data dilakukan kredibilitas. Kredibilitas tersebut meliputi triangulasi, meningkatkan ketekunan, serta kecukupan referensi. Analisis data dalam penelitian ini meliputi 4 (empat) tahap yaitu pengumpulan data, penyajian data, reduksi data dan penarikan kesimpulan.

\section{HASIL}

Berdasarkan hasil observasi di lapangan, didapatkan informasi bahwa sebelumnya sekolah masih menggunakan pengarsipan konvensional atau manual. Namun sejak sekitar 3 tahun memimpin sekolah, kepala sekolah baru, telah mengembangkan beberapa kemajuan, salah satunya dalam hal pengarsipan surat. Pengarsipan surat sekarang sudah menggunakan digital melalui aplikasi yaitu dengan menggunakan Microsoft Acces.

Pengembangan dalam arsip surat ini dilakukan dengan cara kepala sekolah mendatangkan ahli dari luar untuk melakukan pelatihan pada pendidik agar dapat mengubah cara arsip surat. Usaha kepala sekolah ini dilakukan untuk mengembangkan Sumber Daya Manusia (SDM) yang ada di sekolah agar sekolah tidak tertinggal dengan sekolah lain. Mengingat semua hal yang ada pada dunia pendidikan saat ini sudah berbantuan teknologi yang sifatnya online agar memudahkan semua orang untuk mengaksesnya. Tata cara pengarsipan surat dilakukan dengan mengelompokkan surat berdasarkan jenis surat dan bulan pembuatan surat. Pihak sekolah merasa bahwa dengan adanya arsip surat ini memudahkan pendidik dalam melakukan pekerjaannya dalam segi efisien waktu yang lebih cepat ketika membutuhkan arsip surat yang dibutuhkan dalam kegiatan di sekolah.

Berdasarkan observasi dan wawancara yang telah peneliti lakukan di SMP Islam Ma'arif 02 Malang menyebutkan bahwa pengarsipan digital ini dilakukan karena dirasa lebih mudah dibanding pengarsipan manual. Pengarsipan manual memiliki kekurangan yang dirasakan sekolah yaitu masih banyaknya ruang yang perlu disediakan untuk surat, kurang efisien dalam penggunaan ATK yaitu kertas dan tinta karena harus dicetak berupa hardfile dan perlu map khusus pada setiap bulannya agar mengetahui pada bulan apa saja terdapat kegiatan apa yang dilakukan sekolah.

Pengarsipan konvensional yang sebelumnya dijalankan oleh sekolah, dijelaskan bahwa dalam kegiatan kesehariannya memakan waktu yang banyak, misalnya apabila pegawai mencari surat bulan Juni maka pegawai tersebut harus mencari di map-map bulan Juni dan melihat banyak surat di dalamnya, hal ini berbeda dengan pengarsipan digital yang saat ini dijalankan oleh sekolah yang apabila dibutuhkan maka dapat mencari dalam aplikasi tersebut dengan surat yang diinginkan setiap waktu oleh sekolah. Hal ini juga terjadi karena dorong an 
perkembangan zaman yang mengharuskan sekolah harus lebih tanggap dalam kegiatan pengarsipan yang dilakukan, tidak terlepas dari itu saja apabila ketika di sebuah lembaga pendidikan melakukan proses audit manajemen pendidikan bagian persuratan atau pengarsipan dengan bantuan sistem teknologi akan lebih memudahkan apabila pihak pengaudit meminta data surat dengan cepat dan tepat.

Berdasarkan hasil observasi dan wawancara di SMP Islam Ma'arif 02 Kota Malang dengan adanya pengarsipan digital sekolah menyebutkan proses audit pengarsipan menjadi lebih optimal dikarenakan pengarsipan digital pengaksesannya lebih mudah, penyajian data lebih lengkap, pencarian surat lebih cepat. Sehingga dengan pelaksanaan pengarsipan menggunakan aplikasi digital maka sekolah sangat terbantu melakukan audit pengarsipan. proses ini juga dilakukan oleh sekolah dengan terus melakukan pengoptimalan dari segi SDM yang dimiliki agar terus terasah memahami penggunaan proses audit pengarsipan dengan menggunakan teknologi masa kini.

\section{PEMBAHASAN}

Hasil penelitian menunjukkan bahwa sejak sekitar 3 tahun memimpin sekolah, kepala sekolah baru telah mengembangkan beberapa kemajuan, salah satunya dalam hal pengarsipan surat. Hal ini menunjukkan bahwa kepala sekolah sebagai pemimpin tertinggi di sekolah harus menjadi pelopor perubahan, sehingga sekolah dapat berkembang (Adha et al., 2019; Juharyanto, 2017; Richardson \& McLeod, 2011; Sunarni et al., 2018). Sebelumnya sekolah masih menggunakan pengarsipan konvensional atau manual, pengembangan aplikasi digital terdapat proses yang dilakukan untuk mengubah dari arsip konvensional ke arsip digital. Tahap-tahap tersebut diantaranya (Hakim, 2015): (1) tahap pemilihan, yaitu memilih arsip berdasarkan seberapa tinggi penggunaan arsip tersebut; (2) tahap pemindaian, dalam tahap ini harus dilakukan dengan teliti untuk mendapatkan master arsip digital; (3) tahap penyesuaian, yaitu menyesuaikan nama file dengan jenis arsip; (4) tahap pendaftaran, yaitu membuat daftar dengan mencantumkan informasi berupa nomor urut serta kode arsip; dan (5) tahap pembuatan berita acara, yaitu dilakukan dengan mencantumkan legalisasi dari pejabat yang berwenang, pihak penanggung jawab, jenis perangkat yang digunakan, serta jenis komputer yang digunakan.

Setelah dilakukan berbagai tahap untuk mengubah arsip konvensional menjadi arsip digital, maka akan dapat dirasakan berbagai kemudahan serta manfaat yang diperoleh. Menurut pihak sekolah sendiri manfaat dari arsip surat secara digital yaitu memudahkan pendidik dalam melakukan pekerjaannya. Hal ini sesuai dengan pendapat Muhidin et al. (2018) mengenai 
manfaat arsip digital yaitu: (1) memudahkan dalam sistem penyimpanan; (2) lebih mudah dan cepat untuk menemukan arsip; (3) lebih praktis dan aman; (4) hemat hemat tempat, karena tidak perlu ruang khusus untuk menyimpan arsip; (5) memudahkan dalam kegiatan berbagi arsip; dan (6) lebih mudah dalam memperbaiki apabila terdapat data yang rusak.

Hasil penelitian menyebutkan kelebihan dari penggunaan aplikasi arsip digital yaitu memudahkan pencarian surat dan tidak memerlukan banyak tempat dalam penyimpanannya. Hal tersebut sesuai dengan pendapat yang dijelaskan oleh Pradana (dalam Putranto, 2018) bahwa kelebihan dari pengarsipan digital yaitu: (1) tidak membutuhkan ruang kearsipan; (2) tidak membutuhkan kertas dan tinta cetak baik printer maupun mesin fotocopy untuk penggandaan surat; (3) penggunaan waktu yang lebih efisien dalam mengakses arsip; (4) penekanan kebutuhan SDM; dan (5) memperkecil kemungkinan untuk menghilangkan maupun menghancurkan suatu arsip. Dapat disimpulkan bahwa kelebihan pengarsipan digital dapat mempermudah pencarian surat dan tidak memerlukan biaya yang lebih dalam pencetakan surat maupun biaya dalam penyimpanan serta penggunaan waktu yang relatif efisien.

Hasil penelitian menyatakan dengan adanya pengarsipan digital maka proses audit pengarsipan lebih optimal karena pengarsipan digital tersebut dapat lebih mudah dalam mengakses, penyajian data lebih lengkap dan rinci, serta pencarian surat akan lebih cepat didapatkan sehingga dalam penggunaan aplikasi digital ini sekolah dapat terbantu dalam melakukan audit pengarsipan. Hal tersebut sesuai dengan pendapat Muhidin et al. (2018) bahwa perkembangan teknologi sangat memudahkan pengelolaan arsip secara elektronik atau digital. Adanya penanganan dalam pengarsipan secara digital dapat memberikan dampak yang cukup baik karena perkembangan yang terjadi dalam era sekarang ini lebih memudahkan para pelanggan teknologi dalam pembuatan surat dan pencarian surat yang diinginkan serta dapat bervariasi jenis-jenis aplikasi pengarsipan surat yang dapat memudahkan dalam proses audit pengarsipan (Asogwa, 2012; Nurabadi et al., 2019). Dapat juga dijelaskan oleh Triwiyanto \& Nurabadi (2015) bahwasanya audit manajemen pendidikan merupakan kegiatan untuk mengevaluasi terhadap efektivitas dan efisiensi operasi suatu lembaga pendidikan. Dapat disimpulkan bahwa pengarsipan digital ini dapat mudah untuk melakukan proses audit atau proses dalam mengevaluasi dari efektivitas dan efisiensi dari aplikasi digital yang dilakukan oleh sekolah.

\section{KESIMPULAN}

Berdasarkan uraian di atas dapat disimpulkan bahwa pengarsipan digital di SMP Islam Ma'arif 02 Malang dapat mengoptimalkan pelaksanaan audit persuratan. Pengauditan yang ada di 
sekolah ini telah menggunakan digital dengan menggunakan aplikasi microsoft acces. Banyaknya kelebihan yang dirasakan sekolah saat adanya arsip digital ini memudahkan pendidik dalam melakukan tugasnya untuk mengarsipkan surat. Mengingat arsip surat merupakan rekaman kegiatan atau peristiwa dalam bentuk dan proses yang sesuai dengan perkembangan teknologi. Dengan demikian proses arsip surat dapat dilakukan secara optimal dengan menggunakan digital yang cara pengarsipannya dapat dilakukan dengan lengkap dan rinci dan efisien dalam pencarian data arsip surat ketika proses audit di sekolah berlangsung. Adanya proses ini tidak terlepas dari bantuan dari pihak sekolah dan dukungan dari proses keikutsertaan dalam program pelatihan sebagai optimalisasi pelaksanaan audit pengarsipan.

Berdasarkan uraian artikel di atas, saran yang dapat disampaikan oleh peneliti yaitu agar lembaga pendidikan lebih melakukan pengembangan aplikasi pengarsipan digital sesuai dengan kemajuan teknologi dalam proses audit pengarsipan dapat optimal. Kepala sekolah harus berupaya untuk meningkatkan kualitas sumber daya manusia organisasi bertujuan untuk meningkatkan kinerja dan meningkatkan penggunaan teknologi di bidang lain di sekolah dan harus ada dukungan dari seluruh warga di sekolah agar segala upaya yang dilakukan oleh sekolah agar mencapai tujuan utamanya agar proses audit pengarsipan surat dapat terlaksana dengan baik, cepat, dan efisien mengikuti perkembangan zaman namun juga tetap pada aturan aturan yang berlaku pada setiap proses audit yang dilaksanakan.

\section{Acknowledgement}

Penulis mengucapkan terima kasih kepada Dekan Fakultas Ilmu Pendidikan Universitas Negeri Malang yang telah memberikan ijin untuk melakukan penelitian ini sehingga penelitian ini dapat terselesaikan. Terima kasih disampaikan kepada rekan penulis yang berkontribusi pada artikel ini secara langsung atau tidak langsung.

\section{DAFTAR PUSTAKA}

Adha, M. A., Supriyanto, A., \& Timan, A. (2019). Strategi peningkatan mutu lulusan madrasah menggunakan diagram fishbone. Tarbawi: Jurnal Keilmuan Manajemen Pendidikan, 5(01), 11-22. https://doi.org/10.32678/tarbawi.v5i01.1794

Arifin, I., Juharyanto, Mustiningsih, \& Taufiq, A. (2018). Islamic crash course as a leadership strategy of school principals in strengthening school organizational culture. SAGE Open, 8(3), 1-10. https://doi.org/10.1177/2158244018799849

Asogwa, B. E. (2012). The challenge of managing electronic records in developing countries: Implications for records managers in sub saharan africa. Records Management Journal, 22(3), 198-211. https://doi.org/10.1108/09565691211283156

Berisha, F. (2015). Archives management and permanent storage of documents. Atlantis, 25(1), 
153-161. https://doi.org/10.33700/2670-451x.25.1.153-161(2015)

Cheng, E. C. K. (2018). Managing records and archives in a Hongkong school: a Case Study. Records Management Journal, 28(2), 204-216. https://doi.org/10.1108/RMJ-02-20170004

Creswell, J. C. (2018). Research design: Pendekatan metode kualitatif, kuantitatif, dan campuran. Yogyakarta: Pustaka Pelajar.

Darmaji, Supriyanto, A., Timan, A., \& Adha, M. A. (2020). Sistem penjaminan mutu internal sekolah di satuan pendidikan dasar (studi kasus di SD plus al-Kautsar Malang). Jurnal Pendidikan Dasar Nusantara, 5(2), 172-186.

Dubey, A. D. (2016). ICT in education. International Journal of Information and Communication Technology Education, 12(4), 37-50. https://doi.org/10.4018/ijicte.2016100104

Garza, E., Drysdale, L., Gurr, D., Jacobson, S., \& Merchant, B. (2014). Leadership for school success: Lessons from effective principals. International Journal of Educational Management, 28(7), 798-811. https://doi.org/10.1108/IJEM-08-2013-0125

Ghavifekr, S., Razak, A., Ghani, M., Ran, N., Meixi, Y., \& Tengyue, Z. (2014). ICT Integration in education: Incorporation for teaching \& learning improvement. Malaysian Online Journal of Educational Technology, 2(2), 24-45.

Hakim, T. D. (2015). Pengelolaan arsip di era teknologi informasi. Jurnal Ilmu Budaya, 11(2), 109-117. https://doi.org/10.31849/jib.v11i2.1102

Hammond, M. (2014). Introducing ICT in schools in England: Rationale and consequences. British Journal of Educational Technology, 45(2), 191-201. https://doi.org/10.1111/bjet.12033

Juharyanto. (2017). Implementation of principal personality competency as a change agent on school achievement in remote area one roof school. 2nd International Conference on Educational Management and Administration (CoEMA 2017), 34-38. https://doi.org/10.2991/coema-17.2017.7

Kettunen, J. (2012). External and internal quality audits in higher education. TQM Journal, 24(6), 518-528. https://doi.org/10.1108/17542731211270089

Latif, F., \& Pratama, A. W. (2015). Perancangan sistem informasi manajemen arsip elektronik. Jurnal Akuntansi, Ekonomi Dan Manajemen Bisnis, 3(1), 21-31.

Lindquist, E. A., \& Huse, I. (2017). Accountability and monitoring government in the digital era: Promise, realism and research for digital-era governance. Canadian Public Administration Journal, 60(4), 627-656. https://doi.org/10.1111/capa.12243

Lindqvist, H. M., \& Pettersson, F. (2019). Digitalization and school leadership: On the complexity of leading for digitalization in school. International Journal of Information and Learning Technology, 36(3), 218-230. https://doi.org/10.1108/IJILT-11-2018-0126

Muhidin, S. A., Winata, H., \& Santoso, B. (2018). Pengelolaan arsip digital. Pendidikan Bisnis \& Manajemen, 2(3), 425-426.

Nurabadi, A., Sucipto, \& Juharyanto. (2019). The implementation of school-based management to improve the quality of education in laboratory schools. International Conference on Education and Technology (ICET 2018), 190-196. https://doi.org/10.2991/icet-18.2018.36

Putranto, W. A. (2018). Pengelolaan arsip di era digital: Mempertimbangkan kembali sudut 
pandang pengguna. Diplomatika: Jurnal Kearsipan Terapan, 1(1), 1-12. https://doi.org/10.22146/diplomatika.28253

Richardson, J. W., \& McLeod, S. (2011). Technology leadership in native american schools. Journal of Research in Rural Education (Online), 26(7), 1-14.

Russel, J. P. (2012). The ASQ auditing handbook: principles, implementation, and use (Fourth Edition). ASQ Quality Press.

Saputra, B. R., Adha, M. A., Ariyanti, N. S., \& Gunawan, I. (2019). Tips for principal in managing one roof school ( SATAP) in Underdeveloped Area. 4th International Conference on Education and Management (CoEMA 2019), December. https://doi.org/10.2991/coema-19.2019.10

Sunarni, S., Kusumaningrum, D. E., \& Benty, D. D. N. (2018). Pemetaan gaya dan tipe kepemimpinan kepala sekolah. Jurnal Sekolah Dasar: Kajian Teori Dan Praktik Pendidikan, 27(1), 19-29. https://doi.org/10.17977/um009v27i12018p019

Triwiyanto, T., \& Nurabadi, A. (2015). Audit manajemen bidang pendidikan. Universitas Negeri Malang Press.

Ulfatin, N. (2015). Metode penelitian kualitatif di bidang pendidikan: Teori dan aplikasinya. Media Nusa Creative.

Undang-Undang Nomor 43 Tahun 2009 Pasal 1 Ayat 2 tentang Kearsipan.

Zulkarnain, W., \& Sumarsono, R. B. (2015). Manajemen perkantoran profesional. Bandung: Gunung Samudera. 